\title{
Precipitation measurement intercomparison in the Qilian Mountains, north-eastern Tibetan Plateau
}

\author{
R. Chen, J. Liu, E. Kang, Y. Yang, C. Han, Z. Liu, Y. Song, W. Qing, and P. Zhu \\ Qilian Alpine Ecology and Hydrology Research Station, Key Laboratory of Inland River Ecohydrology, Cold and Arid \\ Regions Environmental and Engineering Research Institute, Chinese Academy of Sciences, Lanzhou 730000, China \\ Correspondence to: R. Chen (crs2008@1zb.ac.cn)
}

Received: 7 March 2015 - Published in The Cryosphere Discuss.: 31 March 2015

Revised: 14 October 2015 - Accepted: 15 October 2015 - Published: 28 October 2015

\begin{abstract}
An experimental field study of wind-induced bias in precipitation measurements was conducted from September 2010 to April 2015 at a grassland site $\left(99^{\circ} 52.9^{\prime} \mathrm{E}\right.$, $38^{\circ} 16.1^{\prime} \mathrm{N} ; 2980 \mathrm{~m}$ ) in the Hulu watershed in the Qilian Mountains, on the north-eastern Tibetan Plateau, in China. The experiment included (1) an unshielded Chinese standard precipitation gauge $\left(\mathrm{CSPG}_{\mathrm{UN}}\right.$; orifice diameter $=20 \mathrm{~cm}$, height $=70 \mathrm{~cm}),(2)$ a single Alter shield around a CSPG $\left(\mathrm{CSPG}_{\mathrm{SA}}\right),(3)$ a CSPG in a pit (CSPGPIT) and (4) a DoubleFence International Reference (DFIR) with a Tretyakov-

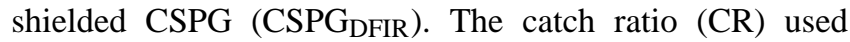
the $\mathrm{CSPG}_{\mathrm{DFIR}}$ as a reference $\left(\mathrm{CR}=\mathrm{CSPG}_{X} / \mathrm{CSPG}_{\mathrm{DFIR}}\right.$, $\% ; X$ denotes UN, SA or PIT). The results show that the $\mathrm{CSPG}_{\mathrm{SA}}, \mathrm{CSPG}_{\mathrm{PIT}}$ and $\mathrm{CSPG}_{\mathrm{DIFR}}$ caught $0.9,4.5$ and $3.4 \%$ more rainfall; $7.7,15.6$ and $14.2 \%$ more mixed precipitation (snow with rain, rain with snow); $11.1,16.0$ and 20.6\% more snowfall and 2.0, 6.0 and 5.3\% more precipitation (of all types), respectively, than the CSPG from September 2012 to April 2015. The CSPG $\mathrm{CSPG}_{\text {DFIR }}$ caught 3.6 and $2.5 \%$ more rainfall; 7.3 and $6.0 \%$ more mixed precipitation; 4.4 and $8.5 \%$ more snowfall; and 3.9 and $3.2 \%$ more total precipitation, respectively, than the $\mathrm{CSPG}_{\mathrm{SA}}$. However, the $\mathrm{CSPG}_{\mathrm{DFIR}}$ caught $1.0 \%$ less rainfall; $1.2 \%$ less mixed precipitation; $3.9 \%$ more snowfall and $0.6 \%$ less total precipitation than the CSPG From most to least precipitation measured, the instruments ranked as follows: for rain and mixed precipitation, $\mathrm{CSPG}_{\mathrm{PIT}}>\mathrm{CSPG}_{\mathrm{DFIR}}>\mathrm{CSPG}_{\mathrm{SA}}>\mathrm{CSPG}_{\mathrm{UN}}$; for snowfall, $\mathrm{CSPG}_{\text {DFIR }}>\mathrm{CSPG}_{\mathrm{PIT}}>\mathrm{CSPG}_{\mathrm{SA}}>\mathrm{CSPG}_{\mathrm{UN}}$. The CR vs. $10 \mathrm{~m}$ wind speed for the period of precipitation indicated that with increasing wind speed from 0 to $8.0 \mathrm{~m} \mathrm{~s}^{-1}$, the $\mathrm{CR}_{\mathrm{UN} / \mathrm{DFIR}}$ and $\mathrm{CR}_{\mathrm{SA} / \mathrm{DFIR}}$ for rainfall decreased slightly. For
\end{abstract}

mixed precipitation, the wind speed showed no significant effect on $\mathrm{CR}_{\mathrm{UN} / \mathrm{DFIR}}$ and $\mathrm{CR}_{\mathrm{SA} / \mathrm{DFIR}}$ below $3.5 \mathrm{~m} \mathrm{~s}^{-1}$. For snowfall, the $\mathrm{CR}_{\mathrm{UN} / \mathrm{DFIR}}$ and $\mathrm{CR}_{\mathrm{SA} / \mathrm{DFIR}}$ vs. wind speed showed that $\mathrm{CR}$ decreased with increasing wind speed. The precipitation measured by the shielded gauges increased linearly relative to that of the unshielded gauges. However, the increase in the ratio of the linear correlation should depend on specific environmental conditions. A comparison of the wind-induced bias indicates that the CSPGPIT could be used as a reference gauge for rain, mixed and snow precipitation events at the experimental site. As both the PIT and DFIR effectively prevented wind from influencing the catch of the precipitation gauge, the $\mathrm{CR}_{\mathrm{PIT} / \mathrm{DFIR}}$ had no relationship with wind speed. Cubic polynomials and exponential functions were used to quantify the relationship between catch ratio and wind speed. For snow, for both event and daily scales, the $\mathrm{CR}_{\mathrm{UN} / \mathrm{DFIR}}$ and $\mathrm{CR}_{\mathrm{SA} / \mathrm{DFIR}}$ were significantly related to wind speed; while for rain and mixed precipitation, only the event scale showed a significant relationship.

\section{Introduction}

In western China, mountainous watersheds are the source areas of runoff generation and water resources, and accurate precipitation measurements are extremely important for calculating the water balance and understanding the water cycle processes in these high mountains. It is widely recognised that precipitation gauge measurements contain systematic errors caused mainly by wetting, evaporation loss and windinduced undercatch, and that snowfall observation errors are very large under high wind (Sugiura et al., 2003). These er- 
rors affect the evaluation of available water in a large number of economic and environmental applications (Tian et al., 2007; Ye et al., 2012).

For decades, all knowledge of precipitation measurement errors has relied on field experiments. Back in 1955, the World Meteorological Organization (WMO) conducted the first precipitation measurement intercomparisons (Rodda, 1973). The reference standard was a British Meteorological Office Snowdon-type (Mk2) gauge elevated $1 \mathrm{~m}$ above the ground and equipped with an Alter wind shield, which did not accurately reflect the precipitation level (Struzer, 1971). Rodda (1967) compared the catch of a UK 5 in. manual gauge, exposed normally at the standard height of $30.5 \mathrm{~cm}$ above ground, with a Koschmieder-type gauge exposed in a pit. The gauge in the pit caught $6 \%$ more precipitation than the normally exposed gauge. In the second WMO precipitation measurement intercomparison (rain, 1972-1976), a pit with an anti-splash grid was designated the reference standard shield for rain gauges (Sevruk and Hamon,1984). In the third WMO precipitation measurement intercomparison (snow, 1986-1993), the Double Fence International Reference (DFIR) with a Tretyakov shield was designated the reference standard snow gauge configuration (Goodison et al., 1998). In the fourth WMO precipitation measurement intercomparison (rain intensity, 2004-2008), different principles were tested to measure rainfall intensity and define a standardised adjustment procedure (Lanza et al., 2005). Because automation of precipitation measurements was widespread, the WMO Commission for Instruments and Methods of Observation (CIMO) organised the WMO Solid Precipitation Intercomparison Experiment (WMO-SPICE; Wolff et al., 2014) to define and validate automatic field instruments as references for gauge intercomparison, and to assess the automatic systems and operational networks for precipitation observations. The experiments and investigations are ongoing, and the WMO-SPICE project confirms the DFIR shield to be a part of the reference configurations.

The DFIR shield has been operated at 25 stations in 13 countries around the world (Golubev, 1985; Yang et al., 1993; Sevruk et al., 2009), but deviations from the DFIR measurements vary by gauge type and precipitation type (Goodison et al., 1998). In China, the Chinese standard precipitation gauge (CSPG) and the Hellmann gauge were first compared using the DFIR shield as a reference configuration at the Tianshan site $\left(43^{\circ} 7^{\prime} \mathrm{N}, 86^{\circ} 49^{\prime} \mathrm{E} ; 3720 \mathrm{~m}\right)$, during the third WMO precipitation measurement intercomparison experiment from 1985 to 1987 (Yang, 1988; Yang et al., 1991). The wetting loss, evaporation loss, wind-induced undercatch and trace precipitation of the CSPGs were well quantified based on the large volume of observation data at the Tianshan site (Yang et al., 1991). For wind-induced undercatch, the derived CSPG catch ratio equations were based on the $10 \mathrm{~m}$ height wind speed at the Daxigou meteorological station $\left(43.06^{\circ} \mathrm{N}, 86.5^{\circ} \mathrm{E} ; 3540 \mathrm{~m}\right)$ and at several other standard meteorological stations near the measurement site
(Yang, 1988; Yang et al., 1991). This intensive experimental field study created a basis for later work on the correction of systematic bias in precipitation measurements in China. From 1992 to 1998, Ren and Li (2007) conducted an intercomparison experiment at 30 sites (the altitude ranged from about 4.8 to $3837 \mathrm{~m}$ ) using the pit as a reference across China, and a total of 29276 precipitation events were observed. Yang et al. (1999) emphasised that among all known systematic errors in precipitation observation, wind-induced gauge undercatch was the greatest source of bias, particularly in cold regions, and recommended testing for the application of adjustment techniques in regional observation networks. In the mountainous watersheds of western China, the complex high mountain topography and underlying surfaces with inhomogeneous glaciers, permafrost and alpine vegetation make the wind vector field in the lower boundary layer extremely complex, causing equally complex wind field deformations over the gauge orifice. At present, our investigation of wind-induced error in precipitation measurements is based on the horizontal time-averaged wind speed. Thus it is reasonable to investigate the regional average characteristics of wind fields and the interaction between wind fields and the precipitation gauges at our present research level. In addition to Yang's experimental field work on systematic error adjustments for precipitation measurements in eastern Tianshan from 1985 to 1987 (Yang, 1988), it is necessary to carry out field experiments on precipitation measurement in the other mountainous regions of western China.

Adjustment procedures and reference measurements were developed during several WMO international precipitation measurement intercomparisons (Goodison et al., 1998; Sevruk et al., 2009; Yang, 2014). The application of all of these adjustment procedures and methods depends on both environmental factors and precipitation features, and among the factors considered, wind speed and temperature have been found to have the most important effect on gauge catch (Yang et al., 1999). Ye et al. (2004) developed a bias-error adjustment method for CSPGs based on observation data from 1985 to 1997 at the Tianshan site (Yang et al., 1991), and found a new precipitation trend in the adjusted precipitation data for the past 50 years in China (Ding et al., 2007). The new precipitation adjustment has improved the precipitation estimation in water balance computation for many basins in China (Ye et al., 2004, 2012; Tian et al., 2007). Ma et al. (2014) used the adjusted equations from neighbouring countries in addition to the experimental results from eastern Tianshan in China (Yang et al., 1991) to correct for windinduced errors on the Tibetan Plateau. However, the precipitation gauges used in the neighbouring countries were the Tretyakov, MK2, Nepal203, Indian standard and US 8 in. As the world's third polar region, the Tibetan Plateau and its surrounding mountain ranges is ecologically fragile and the source of several large rivers in China and neighbouring countries, and accurate precipitation data are urgently needed for water resource exploitation and environmental protec- 


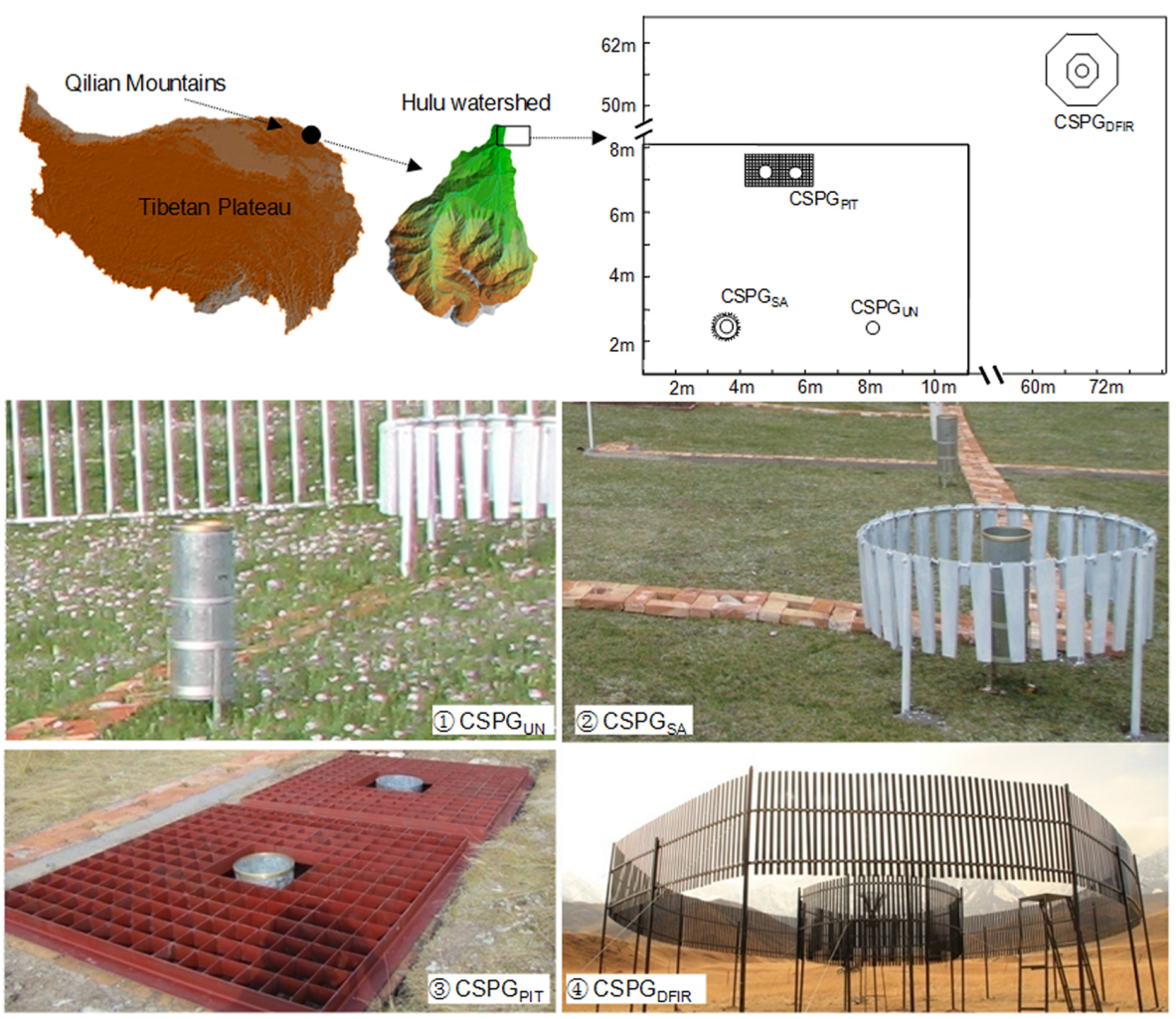

Figure 1. Precipitation gauge intercomparison experiment in the Qilian Mountains, Tibetan Plateau.

tion. The problem is how to apply and test the already established principal adjustment procedures and methods to correct for precipitation measurement errors in the vast plateau and high mountains of western China, where climatic and environmental conditions are highly complex and variable, both spatially and temporally. To quantify and understand the specific influences of climatic and environmental factors on wind-induced bias in precipitation measurements in a mountain watershed, and then test and parameterise the adjustment equations, an intercomparison experiment was carried out for nearly 5 years on both unshielded and shielded CSPGs in a watershed in the Qilian Mountains on the north-eastern Tibetan Plateau in China.

The CSPG is the standard manual precipitation gauge that has been used by the China Meteorological Administration (CMA) in more than 700 stations since the 1950s. The Alter shield (Struzer, 1971) was used by the CMA to enhance catch of automatic gauges (Yang, 2014), and the pit and DFIR were used to provide true rainfall and snowfall values for the WMO intercomparison project, respectively (Yang et al., 1999). Therefore, an unshielded CSPG, a single Alter shield CSPG (SA), a DFIR with a Tretyakov-shielded CSPG and a CSPG in a pit were selected as the field experiment of wind-induced bias study. This paper presents the intercomparison experiments and their relevant data, introduces the adjustment methods, discusses wind-induced bias in precipitation measurements by CSPGs for different precipitation phases, analyses the correlations between shielded and unshielded CSPGs and quantifies the relationships between catch ratio and wind speed. The results of the present study are also compared with other studies. In addition, the pit gauge is evaluated for solid precipitation under these climatic conditions. The limitations of the present study are then discussed.

\section{Experiments and methods}

\subsection{Intercomparisons and data}

Precipitation intercomparison experiments (Fig. 1, Table 1) were conducted at a grassland site $\left(99^{\circ} 52.9^{\prime} \mathrm{E}, 38^{\circ} 16.1^{\prime} \mathrm{N}\right.$; $2980 \mathrm{~m}$ ) in the Hulu watershed in the Qilian Mountains, on the north-eastern edge of the Tibetan Plateau, in China. A meteorological cryosphere-hydrology observation system (Chen et al., 2014) was established in 2008 in the Hulu watershed. The mean annual precipitation was $447.2 \mathrm{~mm}$ during 2010-2012 and was concentrated during the warm season from May to September. The annual mean temperature was $1.1^{\circ} \mathrm{C}$, with a July mean $\left(T_{\text {mean }}\right)$ of $12.5^{\circ} \mathrm{C}$ and a January mean of $-12.4^{\circ} \mathrm{C}$ over the years (Table 1$)$. The annual potential evaporation $\left(E_{0}\right)$ was $1102 \mathrm{~mm}$ (Table 1$)$. 
The intercomparative experiments included (1) an unshielded CSPG (CSPG ${ }_{U N}$; orifice diameter $=20 \mathrm{~cm}$, height $=70 \mathrm{~cm}),(2)$ a single Alter shield around a CSPG $\left(\mathrm{CSPG}_{\mathrm{SA}}\right),(3)$ a CSPG in a pit (CSPGPIT) and (4) a DFIR with a Tretyakov-shielded CSPG $\left(\mathrm{CSPG}_{\mathrm{DFIR}}\right)$ (Fig. 1, Table 2). The $\mathrm{CSPG}_{\mathrm{UN}}, \mathrm{CSPG}_{\mathrm{SA}}$ and $\mathrm{CSPG}_{\mathrm{PIT}}$ were installed before September 2010, whereas the CSPG DFIR $_{\text {was installed }}$ in September 2012 (Table 2). In the cold season (October to April), snowfalls dominated the precipitation events, and in the warm season (May to September), rainfall was dominate. The precipitation was measured manually twice a day at 08:00 and 20:00 LT (local time, Beijing time) according to the CMA's standard (CMA, 2007a). In the warm season, precipitation was measured by volume, whereas in the cold season, the funnel and glass bottle were removed from the CSPG and precipitation was weighed under a windproof box. Any frost on the outside surface of the collector was wiped off using a dry hand towel. In rare cases where snow had accumulated on the rim of the collector, this was removed before weighing.

The precipitation phases (snow, rain and mixed) were distinguished using the CMA's standard (CMA, 2007b). Meteorological elements, including maximum air temperature $T_{\max }$ and minimum $T_{\min }$, have been measured in conformation with the meteorological observation manual at the site since June 2009. A meteorological tower was used to measure wind speed (Lisa/Rita, SG GmbH; $W_{\mathrm{s}}$ ), air temperature (HMP45D, Vaisala) and relative humidity (HMP45D, Vaisala) at 1.5 and $2.5 \mathrm{~m}$ heights in association with precipitation measurements (Chen et al., 2014). The time step of the observations of the tower was $30 \mathrm{~s}$ and half-hourly values were obtained. The specific meteorological conditions at the site are summarised in Table 1.

\subsection{Adjustment methods}

This field experiment focused on two key aspects. One was a comparison of the $\mathrm{CSPG}_{\mathrm{UN}}, \mathrm{CSPG}_{\mathrm{SA}}, \mathrm{CSPG}_{\mathrm{PIT}}$ and $\mathrm{CSPG}_{\text {DFIR }}$ gauges. The other was the establishment of adjustment equations for the $\mathrm{CSPG}_{\mathrm{UN}}$ and $\mathrm{CSPG}_{\mathrm{SA}}$ using the $\mathrm{CSPG}_{\mathrm{DFIR}}$ as a reference. To adjust gauge-measured precipitation, Sevruk and Hamon (1984) provided the general formula as

$$
\begin{aligned}
P_{c} & =K P_{\mathrm{g}}+\Delta P_{\mathrm{w}}+\Delta P_{\mathrm{e}}+\Delta P_{\mathrm{t}} \\
& =\Delta P_{\text {DFIR }}+\Delta P_{\mathrm{w}}+\Delta P_{\mathrm{e}}+\Delta P_{\mathrm{t}},
\end{aligned}
$$

where $P_{c}$ is the adjusted precipitation, $K$ is the wind-induced coefficient, $P_{\mathrm{g}}$ is the gauge-measured precipitation. $P_{\mathrm{w}}$ is the wetting loss, $P_{\mathrm{e}}$ is the evaporation loss, $P_{\mathrm{t}}$ is trace precipitation and $P_{\mathrm{DFIR}}$ is the DFIR-shielded precipitation. For loss by the CSPG per observation, $P_{\mathrm{w}}$ is $0.23 \mathrm{~mm}$ for rainfall measurements, $0.30 \mathrm{~mm}$ for snow and $0.29 \mathrm{~mm}$ for mixed precipitation (snow with rain, rain with snow), based on the measurements at the Tianshan site (Yang, 1988; Yang et al., 1991). Ren and Li (2007) reported a mean $P_{\mathrm{w}}$ of

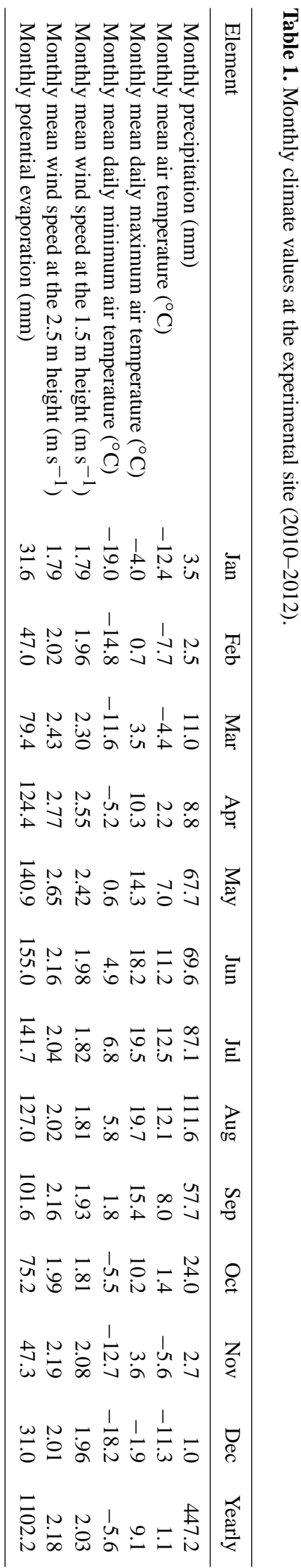


Table 2. The precipitation measurement intercomparison experiment in the Qilian Mountains.

\begin{tabular}{lllccc}
\hline Gauge & Abbreviation & $\begin{array}{l}\text { Size }(\phi \text { denotes orifice diameter } \\
\text { and } h \text { is observation height })\end{array}$ & Start date & $\begin{array}{c}\text { End date } \\
\text { Observation } \\
\text { time }\end{array}$ \\
\hline $\begin{array}{l}\text { Unshielded China standard } \\
\text { precipitation gauge (CMA, 2007a) }\end{array}$ & CSPG & $\phi=20 \mathrm{~cm}, h=70 \mathrm{~cm}$ & Jun 2009 & Apr 2015 & $\begin{array}{l}20: 00 \text { and } \\
08: 00 \mathrm{LT}\end{array}$ \\
\hline $\begin{array}{l}\text { Single Alter shield (Struzer, 1971) } \\
\text { around a CSPG }\end{array}$ & CSPG $_{\mathrm{SA}}$ & $\phi=20 \mathrm{~cm}, h=70 \mathrm{~cm}$ & Jun 2009 & Apr 2015 & $\begin{array}{l}20: 00 \text { and } \\
08: 00 \mathrm{LT}\end{array}$ \\
\hline $\begin{array}{lllll}\text { A CSPG in a pit (Sevruk and } \\
\text { Hamon, 1984) }\end{array}$ & CSPGPIT & $\phi=20 \mathrm{~cm}, h=0 \mathrm{~cm}$ & Sep 2010 & Apr 2015 & $\begin{array}{l}20: 00 \text { and } \\
08: 00 \mathrm{LT}\end{array}$ \\
\hline $\begin{array}{l}\text { DFIR shield (Goodison et al., } \\
\text { 1998) around a CSPG }\end{array}$ & CSPGDFIR & $\phi=20 \mathrm{~cm}, h=3.0 \mathrm{~m}$ & Sep 2012 & Apr 2015 & $\begin{array}{l}20: 00 \text { and } \\
08: 00 \mathrm{LT}\end{array}$ \\
\hline
\end{tabular}

about $0.19 \mathrm{~mm}$ for the total precipitation over eastern China. The CSPG design reduces $P_{\mathrm{e}}$ to a near-zero value smaller than other losses in the warm, rainy season (Ye et al., 2004; Ren and $\mathrm{Li}, 2007)$. In winter, $P_{\mathrm{e}}$ is already small $(0.10$ $0.20 \mathrm{~mm} \mathrm{day}^{-1}$ ) according to the results from Finland (Aaltonen et al., 1993) and Mongolia (Zhang et al., 2004). To prevent evaporation loss in Chinese operational observations on particular days, e.g. hot, dry days or days of snow, precipitation is measured as soon as the precipitation event stops (CMA, 2007a; Ren and Li, 2007). A precipitation event of less than $0.10 \mathrm{~mm}$ is beyond the resolution of the CSPG and is recorded as trace precipitation $\left(P_{\mathrm{t}}\right)$. Ye et al. (2004) recommended assigning a value of $0.1 \mathrm{~mm}$, regardless of the number of trace observations per day. The present study focused on wind-induced bias in precipitation measurement by CSPGs, specifically in high mountain environments, therefore the above mentioned $P_{\mathrm{w}}, P_{\mathrm{e}}$ and $P_{\mathrm{t}}$ values were assumed to be constant in the computation equations.

The WMO proposed Eqs. (2)-(4) to compute the catch ratio of unshielded over shielded Tretyakov gauges on a daily time step for three precipitation types, and the independent variables were wind speed $\left(W_{\mathrm{s}}, \mathrm{ms}^{-1}\right)$ at the gauge height and the daily maximum and minimum temperatures $\left(T_{\max }\right.$, $T_{\min },{ }^{\circ} \mathrm{C}$ ) (Yang et al., 1995; Goodison et al., 1998). These equations are used over a great range of environmental conditions (Goodison et al., 1998).

$$
\begin{aligned}
& \mathrm{CR}_{\text {snow }}=103.1-8.67 W_{\mathrm{s}}+0.3 T_{\max } \\
& \mathrm{CR}_{\text {mix }}=96.99-4.46 W_{\mathrm{s}}+0.88 T_{\max }+0.22 T_{\min } \\
& \mathrm{CR}_{\text {rain }}=100.0-4.77 W_{\mathrm{s}}^{0.56}
\end{aligned}
$$

where $\mathrm{CR}_{\text {snow }}(\%), \mathrm{CR}_{\text {mix }}(\%)$ and $\mathrm{CR}_{\text {rain }}(\%)$ are the catch ratios for snow, mixed precipitation and rain, respectively.

As the CMA stations usually observe wind speed at a height of $10 \mathrm{~m}$, Eqs. (5)-(7) were used for the CSPG catch ratio versus the daily mean wind speed $W_{\mathrm{s}}\left(\mathrm{ms}^{-1}\right)$ at $10 \mathrm{~m}$ (Yang et al., 1991). These equations are based on the large volume of experimental precipitation gauge intercomparison data at the Tianshan site and the wind speed data at the Daxigou station:

$$
\begin{aligned}
& \mathrm{CR}_{\text {snow }}=100 \exp \left(-0.056 W_{\mathrm{s} 10}\right) \quad\left(0<W_{\mathrm{s}}<6.2\right) \\
& \mathrm{CR}_{\text {rain }}=100 \exp \left(-0.04 W_{\mathrm{s} 10}\right) \quad\left(0<W_{\mathrm{s}}<7.3\right) \\
& \mathrm{CR}_{\text {mix }}=\mathrm{CR}_{\text {snow }}-\left(\mathrm{CR}_{\text {snow }}-\mathrm{CR}_{\text {rain }}\right)\left(T_{\text {mean }}+2\right) / 4,
\end{aligned}
$$

where $T_{\text {mean }}$ is the daily mean air temperature $\left({ }^{\circ} \mathrm{C}\right)$.

Referring to Eqs. (2)-(7), two types of equation were used. One is for easy application using $10 \mathrm{~m}$ height wind speed during the period of precipitation in China. These are similar to a revised version of Eqs. (5)-(7). The other type is similar to Eqs. (2)-(4), which use the daily mean wind speed at gauge height. For the CSPGs, the gauge height was $70 \mathrm{~cm}$ (Table 2). The catch ratio uses CSPG $_{\text {DFIR }}$ as the reference $\left(\mathrm{CR}=\mathrm{CSPG}_{X} / \mathrm{CSPG}_{\mathrm{DFIR}}, \% ; X\right.$ denotes $\mathrm{UN}, \mathrm{SA}$ or PIT $)$. The equations were fitted using SPSS software version 19.0 (IBM, 2010) and Microsoft Excel 2007 based on the mathematical least squares method (Charnes et al., 1976). The significance of the equations was evaluated using the $F$ test method (Snedecor and Cochran, 1989). If the significance level $(\alpha)$ of the $F$ test is below 0.05 , the fitted equation is significant. The lower the $\alpha$ value, the greater the significance.

Wind speeds at gauge height $\left(W_{\mathrm{s} 0.7}\right)$ and at $10 \mathrm{~m}$ height $\left(W_{\mathrm{s} 10}\right)$ were calculated using half-hourly wind speed data at $1.5 \mathrm{~m}\left(W_{\mathrm{s} 1.5}\right)$ and $2.5 \mathrm{~m}\left(W_{\mathrm{s} 2.5}\right)$ according to the MoninObukhov theory and the gradient method (Bagnold, 1941; Dyer and Bradley, 1982):

$$
\begin{aligned}
& W_{\mathrm{s} Z}=\frac{\ln Z-\ln Z_{0}}{\ln 1.5-\ln Z_{0}} W_{\mathrm{s} 1.5} \\
& \ln Z_{0}=\frac{W_{\mathrm{s} 2.5} \ln 1.5-W_{\mathrm{s} 1.5} \ln 2.5}{W_{\mathrm{s} 2.5}-W_{\mathrm{s} 1.5}},
\end{aligned}
$$

where $Z$ denotes the height that is referred to.

\section{Results}

From September 2010 to April 2015, a total of 608 precipitation events were recorded at the intercomparison site for $\mathrm{CSPG}_{\mathrm{UN}}, \mathrm{CSPG}_{\mathrm{SA}}$ and $\mathrm{CSPG}_{\mathrm{PIT}}$, respectively (Table 3 ). 
Snow occurred 84 times, mixed precipitation 44 times and rain 480 times during this period. From September 2012 to April 2015, a subset of 283 precipitation events was recorded for the $\mathrm{CSPG}_{\mathrm{UN}}, \mathrm{CSPG}_{\mathrm{SA}}$, CSPGPIT and $\mathrm{CSPG}_{\mathrm{DFIR}}$ gauges, respectively (Table 3). During this period, snow occurred 43 times, mixed precipitation 29 times and rainfall 211 times.

\subsection{Linear correlation of gauge precipitation}

At the 14 WMO intercomparison sites, a strong linear relationship was found between Alter-shielded and unshielded Belfort gauges, Alter-shielded and unshielded NWS 8 in. gauges, and shielded and unshielded Tretyakov gauges for all types of precipitation, with a higher correlation for rain than for snow (Yang et al., 1999). In the present study in the Qilian Mountains, which experiences different environmental conditions compared to the other 14 sites, the same strong linear correlation was found among the four CSPG instalments for rainfall, mixed precipitation and snowfall, with a higher correlation for rain than for mixed precipitation, successively more than for snow (Figs. 2-4). It is therefore considered that in general the precipitation measured by shielded gauges increases linearly with that of unshielded gauges. However, the relative increase in linear correlation should depend on the specific environmental conditions. For solid precipitation, some non-linear factors interfered with the linear relationship to reduce the correlation coefficient.

\subsection{Comparisons of wind-induced bias}

From September 2010 to April 2015, the CSPGPIT caught 4.7 and $3.4 \%$ more rainfall than the $\mathrm{CSPG}_{\mathrm{UN}}$ and the $\mathrm{CSPG}_{\mathrm{SA}}$ respectively $\left(\left(\mathrm{CSPG}_{\mathrm{PIT}}-\mathrm{CSPG}_{\mathrm{UN}}\right) / \mathrm{CSPG}_{\mathrm{UN}} \times 100\right.$; similarly hereinafter). The $\mathrm{CSPG}_{\mathrm{SA}}$ caught $1.3 \%$ more rainfall than the $\mathrm{CSPG}_{\mathrm{UN}}$ (Table 3). During the period from September 2012 to April 2015, the $\mathrm{CSPG}_{\mathrm{SA}}, \mathrm{CSPG}_{\mathrm{PIT}}$ and $\mathrm{CSPG}_{\mathrm{DIFR}}$ caught $0.9,4.5$ and $3.4 \%$ more rainfall, respectively, than the $\mathrm{CSPG}_{\mathrm{UN}}$, and the $\mathrm{CSPG}_{\mathrm{PIT}}$ and $\mathrm{CSPG}_{\mathrm{DFIR}}$ caught 3.6 and $2.5 \%$ more rainfall, respectively, than the CSPG $_{S A}$. However, the $\mathrm{CSPG}_{\mathrm{DFIR}}$ caught $1.0 \%$ less rainfall than the CSPGPIT (Table 3, Fig. 2). These comparative results indicate that the CSPGPIT caught more rainfall and total precipitation compared to the $\mathrm{CSPG}_{\mathrm{DFIR}}$ and other gauges at the experimental site (Table 3, Fig. 2).

A total of 29 mixed precipitation events were observed from September 2012 to April 2015. As shown in Table 3, the CSPGPIT caught the most mixed precipitation among the gauges, capturing $82.2 \mathrm{~mm}$ of mixed precipitation in 29 events, but only $1.1 \mathrm{~mm}$ more than the $\mathrm{CSPG}_{\mathrm{DFIR}}$. The linear relationship between the $\mathrm{CSPG}_{\mathrm{PIT}}$ and $\mathrm{CSPG}_{\mathrm{DFIR}}$ is statistically significant with an $R^{2}$ value of about 0.98 (Fig. 3f). Thus for mixed precipitation, in addition to the CSPG $_{\text {DFIR }}$, the CSPGPIT could also be selected as a reference gauge for the $\mathrm{CSPG}_{\mathrm{UN}}$ and $\mathrm{CSPG}_{\mathrm{SA}}$ at the experimental site.
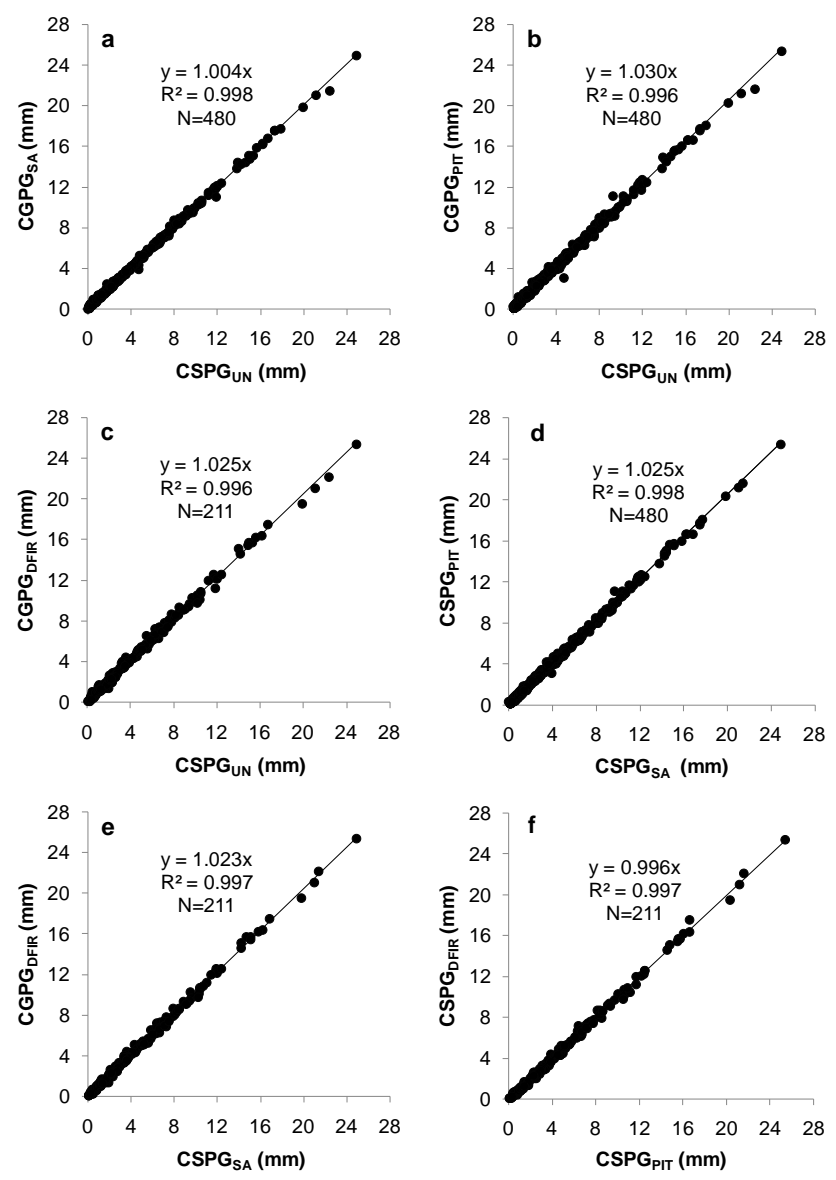

Figure 2. Intercomparison plots among $\mathrm{CSPG}_{\mathrm{UN}}, \mathrm{CSPG}_{\mathrm{SA}}$, $\mathrm{CSPG}_{\mathrm{PIT}}$ and $\mathrm{CSPG}_{\mathrm{DFIR}}$ for the rainfall events from September $2010(\mathbf{a}, \mathbf{b}, \mathbf{d})$ and September 2012 (c, e, f) to April 2015.

From September 2012 to April 2015, the $\mathrm{CSPG}_{\mathrm{SA}}$, CSPG ${ }_{\text {PIT }}$ and CSPG $_{\text {DFIR }}$ caught $11.1,16.0$ and $20.6 \%$ more snowfall, respectively, than the $\mathrm{CSPG}_{\mathrm{UN}}$, and the $\mathrm{CSPG}_{\mathrm{PIT}}$ and $C_{S P G}$ DFIR caught 4.4 and $8.5 \%$ more snowfall, respectively, than the $\mathrm{CSPG}_{\mathrm{SA}}$ (Table 3). Although the $\mathrm{CSPG}_{\mathrm{DFIR}}$ caught $3.9 \%$ more snowfall compared to the CSPGPIT (Table 3), the difference in total snowfall (43 events) between the CSPG $_{\text {DFIR }}$ and CSPG ble 3). Their linear correlation was highly significant with an $R^{2}$ value of 0.994 (Fig. 4f). Blowing snow and thick snow cover have traditionally limited the pit's use as a reference for snowfall and mixed precipitation. At the experimental site, blowing snow was rarely observed and the snow cover was usually shallow. This suggests that the CSPGPIT could be used as a reference gauge for snow precipitation events at the site with shallow snow cover and rare blowing snow event.

To sum up the comparisons of wind-induced bias, from most to least rainfall and mixed precipitation measured, the instruments ranked as follows: $\quad \mathrm{CSPG}_{\mathrm{PIT}}>\mathrm{CSPG}_{\mathrm{DFIR}}>\mathrm{CSPG}_{\mathrm{SA}}>\mathrm{CSPG}_{\mathrm{UN}}$, 


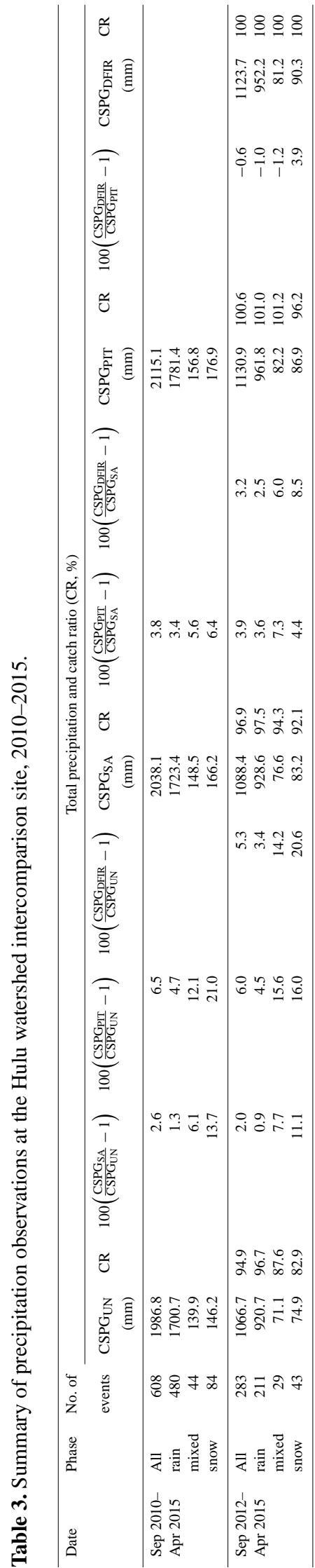

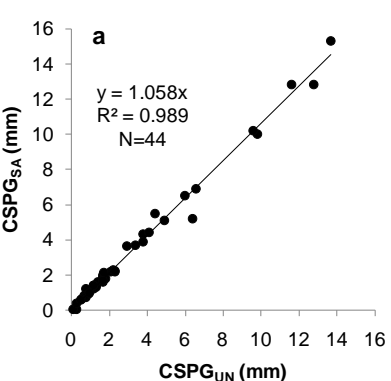
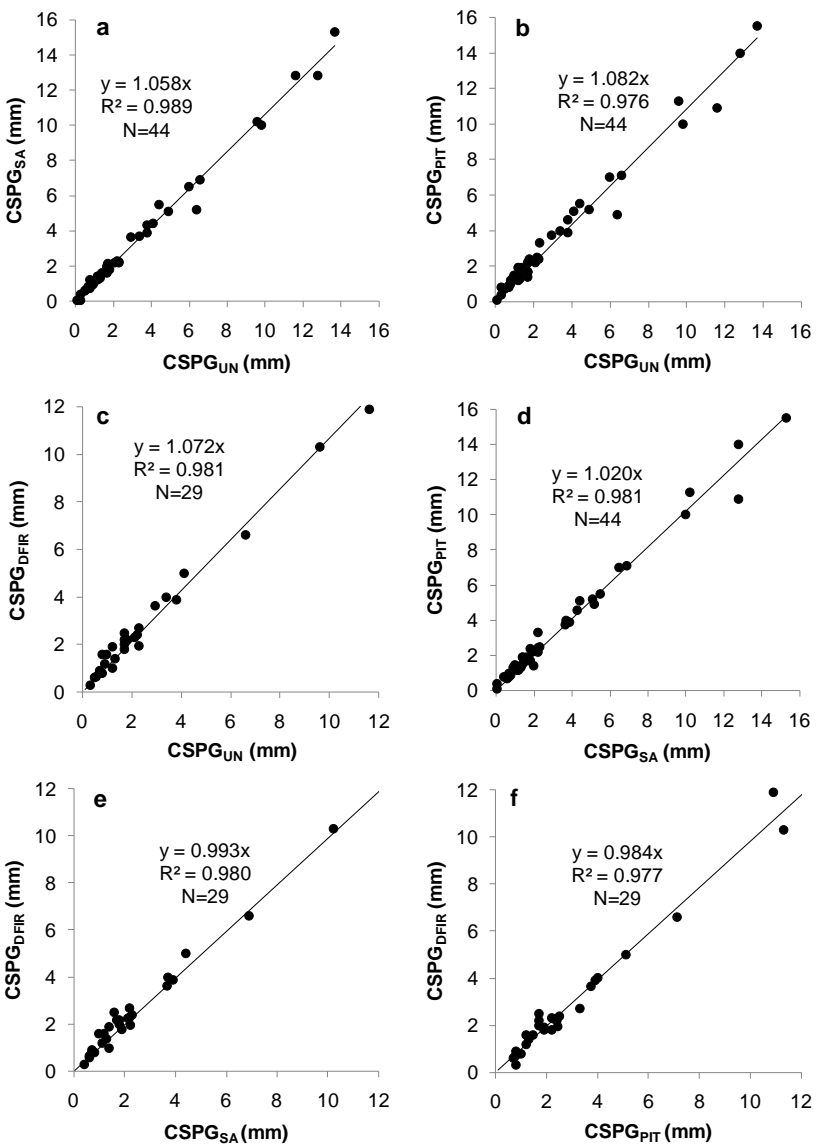

Figure 3. Intercomparison plots among $\mathrm{CSPG}_{\mathrm{UN}}, \mathrm{CSPG}_{\mathrm{SA}}$,

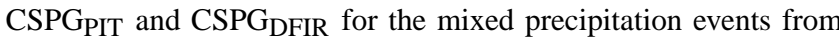
September 2010 (a, b, d) and September 2012 (c, e, f) to April 2015.

while for snowfall their ranking was $\mathrm{CSPG}_{\mathrm{DFIR}}>\mathrm{CSPG}_{\mathrm{PIT}}>\mathrm{CSPG}_{\mathrm{SA}}>\mathrm{CSPG}_{\mathrm{UN}}$.

\subsection{Catch ratio vs. wind speed}

Previous studies have shown that wind speed during the precipitation period is the most significant variable affecting gauge catch efficiency (Metcalfe and Goodison, 1993; Yang et al., 1995; Goodison et al., 1998). Because the CMA stations observe wind speeds at $10 \mathrm{~m}$ height, the $\mathrm{CSPG}_{\mathrm{UN}}$ and CSPG $_{\mathrm{SA}}$ adjustment equations for a single precipitation event were obtained for $10 \mathrm{~m}$ height wind speeds. On the daily scale, adjustment equations similar to Eqs. (2)-(4) were also obtained, based on the daily mean wind speed converted to gauge height ( $0.7 \mathrm{~m}$ for the CSPGs) and air temperature.

To minimise ratio scatter for the different gauges, precipitation events greater than $3.0 \mathrm{~mm}$ are normally selected for the CR vs. wind analysis (Yang et al., 1995, 2014). However, in the Hulu watershed, most snowfall and mixed precipitation events were less than $3.0 \mathrm{~mm}$, thus the limit was reduced and single or daily snowfall and mixed precipitation events greater than $1.0 \mathrm{~mm}$ were selected, while rainfall 

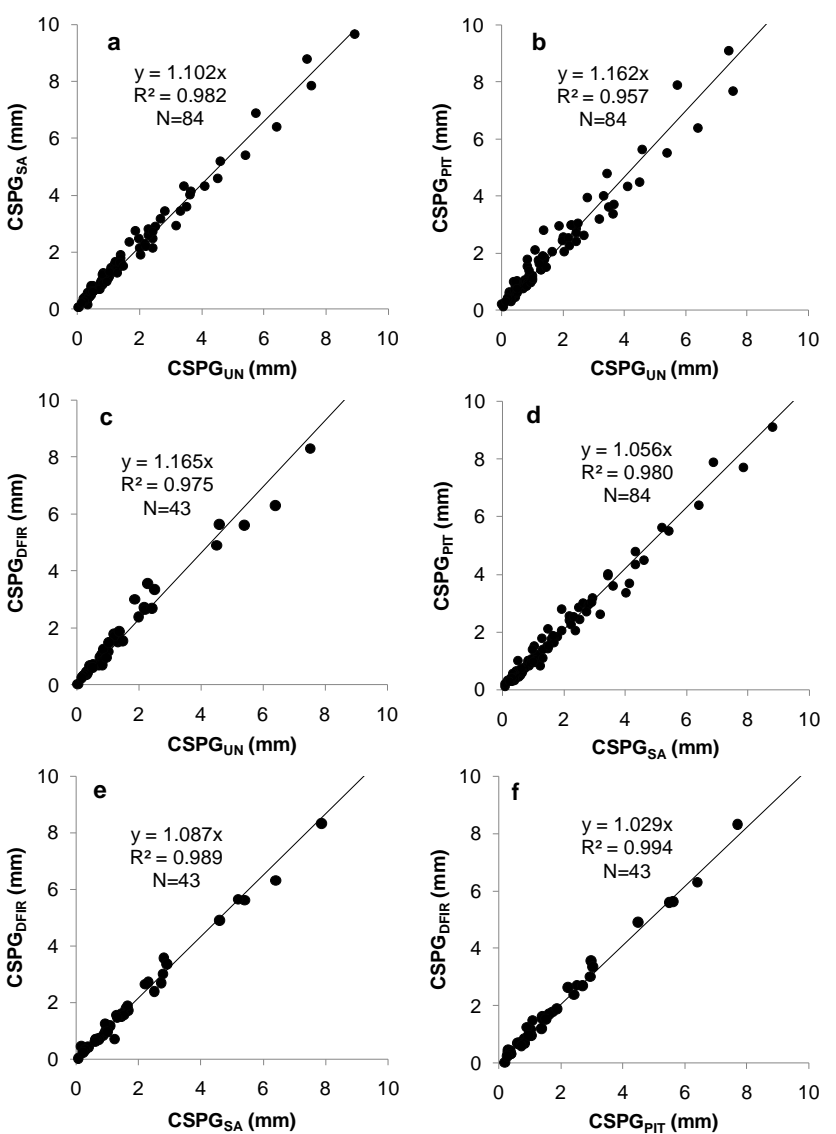

Figure 4. Intercomparison plots among $\mathrm{CSPG}_{\mathrm{UN}}, \mathrm{CSPG}_{\mathrm{SA}}$, CSPG $_{\text {PIT }}$ and CSPG DFIR for the snowfall events from September 2010 (a, b, d) and September 2012 (c, e, f) to April 2015.

events greater than $3.0 \mathrm{~mm}$ were selected. The numbers of selected precipitation events are shown in Table 4. The CR vs. wind speed relationships for different precipitation types were determined using cubic polynomials and exponential functions and are summarised in Table 4 . The $\mathrm{CR}_{\mathrm{UN} / \mathrm{DFIR}}$ and $\mathrm{CR}_{\mathrm{SA} / \mathrm{DFIR}}$ vs. wind speed relationships are statistically significant, but the CRPIT/DFIR vs. $W_{\mathrm{s} 0.7}$ or $W_{\text {s10 }}$ relationships do not pass the $F$ test with $\alpha=0.10$. This phenomenon indicates that both PIT and DFIR are effective in preventing wind from influencing the gauge catch of precipitation, therefore the CR $\mathrm{RIT}_{\text {DFIR }}$ is not related to wind speed.

Figure 5 presents scatter plots for the $\mathrm{CR}_{\mathrm{UN} / \mathrm{DFIR}}$ and $\mathrm{CR}_{\mathrm{SA} / \mathrm{DFIR}}$ vs. wind speed for rainfall. The CRs vary from 80 to $110 \%$. With increasing wind speed, the CRs decrease slightly. Only Eq. (10) shown in Fig. 5 and Table 4 could be used to adjust the rainfall event data from the $\mathrm{CSPG}_{\mathrm{SA}}$. It is significant at 0.03 level (Table 4). As described in Sect. 2.2, Eq.(10) was fitted using the NONLINEAR function in SPSS software (Analyze $\backslash$ Regression $\backslash$ Nonlinear). The $F$ value was then calculated using regression and the residual sum of squares from SPSS (Snedecor and Cochran, 1989). Based on the $F$ value and the degrees of freedom (Df), the significance
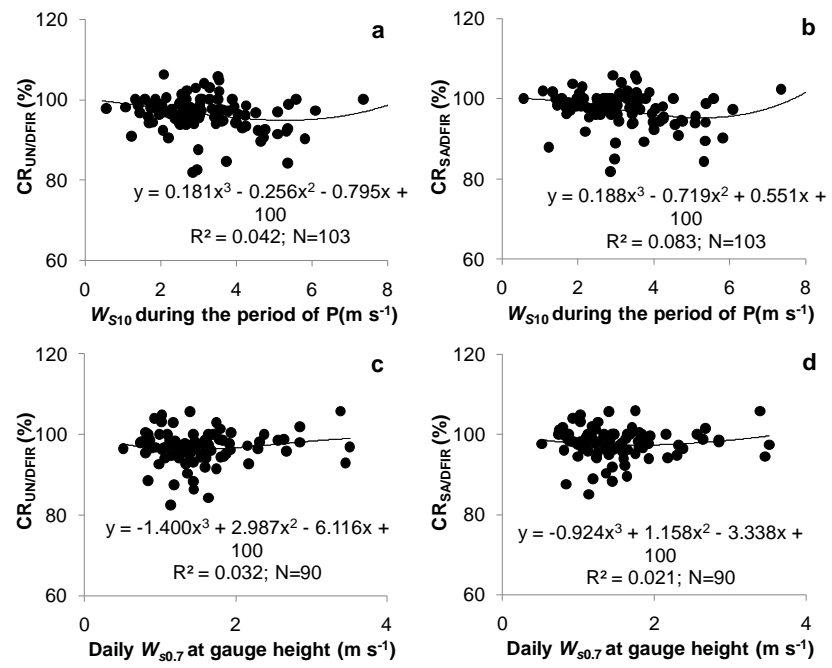

Figure 5. Catch ratios (CRs) vs. wind speed for rainfall events (a, b) and daily rainfall $(\mathbf{c}, \mathbf{d})$ greater than $3.0 \mathrm{~mm}$.
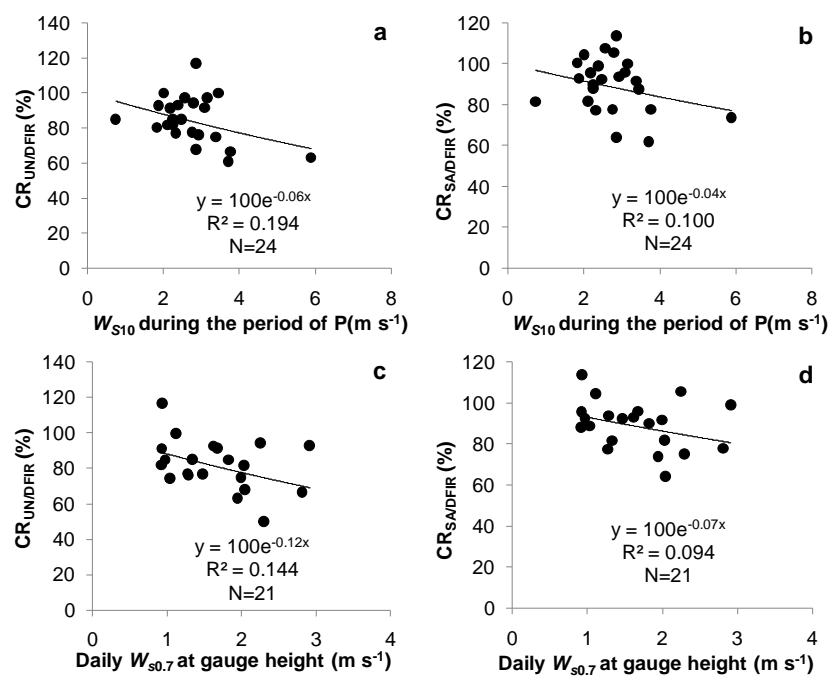

Figure 6. Catch ratios (CRs) vs. wind speed for mixed precipitation events $(\mathbf{a}, \mathbf{b})$ and daily mixed precipitation $(\mathbf{c}, \mathbf{d})$ greater than $1.0 \mathrm{~mm}$.

level $(\alpha)$ was obtained using the FDIST function in Microsoft Excel. Other forms such as the exponential expression were treated in a similar way.

$$
\begin{aligned}
\mathrm{CR}_{\mathrm{SA} / \mathrm{DFIR}, \mathrm{Rain}} & =0.188 W_{\mathrm{s} 10}^{3}-0.719 W_{\mathrm{s} 10}^{2} \\
& +0.551 W_{\mathrm{s} 10}+100 \quad 0<W_{\mathrm{s} 10}<7.4,
\end{aligned}
$$

where $\mathrm{CR}_{\mathrm{SA} / \mathrm{DFIR} \text {,Rain }}$ is the rainfall catch ratio $(\%)$ per observation of the $\mathrm{CSPG}_{\mathrm{SA}}$ and $W_{\mathrm{s} 10}$ is the wind speed at $10 \mathrm{~m}$ during the rainfall period $\left(\mathrm{m} \mathrm{s}^{-1}\right)$.

On the daily scale, the relationships between rainfall $\mathrm{CR}$ and wind speed at gauge height $\left(W_{\mathrm{s} 0.7}\right)$ are also cubic functions, but they do not pass the $F$ test with $\alpha=0.25$ (Table 4). 
Table 4. Catch ratio (CR) vs. wind speed relationships at the Hulu watershed intercomparison site, 2012-2015.

\begin{tabular}{|c|c|c|c|c|c|c|}
\hline $\begin{array}{l}\text { Temporal } \\
\text { scale }\end{array}$ & Phase & Gauges & Catch ratio $(\mathrm{CR})$ vs. wind speed relationships* & $\begin{array}{l}\text { Precipitation } \\
(\mathrm{mm})\end{array}$ & $\begin{array}{l}\text { No. of } \\
\text { events }\end{array}$ & $F$ test \\
\hline \multirow[t]{5}{*}{$\begin{array}{l}\text { Precipitation } \\
\text { event }\end{array}$} & \multirow{3}{*}{ Rain } & $\mathrm{CSPG}_{\mathrm{UN}}$ & $\begin{array}{l}\mathrm{CR}_{\mathrm{UN} / \mathrm{DFIR}, \mathrm{Rain}}=0.181 W_{\mathrm{s} 10}^{3}-0.256 W_{\mathrm{s} 10}^{2}-0.795 W_{\mathrm{s} 10}+100 \\
R^{2}=0.042\end{array}$ & \multirow{3}{*}{$>3.0$} & \multirow{3}{*}{103} & $\alpha=0.23$ \\
\hline & & CSPG $_{S A}$ & $\begin{array}{l}\mathrm{CR}_{\mathrm{SA} / \mathrm{DFIR}, \mathrm{Rain}}=0.188 W_{\mathrm{s} 10}^{3}-0.719 W_{\mathrm{s} 10}^{2}+0.551 W_{\mathrm{s} 10}+100 \\
R^{2}=0.083\end{array}$ & & & $\alpha=0.03$ \\
\hline & & CSPGPIT & $\begin{array}{l}\mathrm{CR}_{\text {PIT/DFIR,Rain }}=0.150 W_{\mathrm{s} 10}^{3}-0.425 W_{\mathrm{s} 10}^{2}+1.119 W_{\mathrm{s} 10}+100 \\
R^{2}=0.008\end{array}$ & & & $\alpha=0.83$ \\
\hline & Mixed & $\begin{array}{l}\mathrm{CSPG}_{\mathrm{UN}} \\
\mathrm{CSPG}_{\mathrm{SA}} \\
\mathrm{CSPG}_{\mathrm{PIT}}\end{array}$ & $\begin{array}{l}\mathrm{CR}_{\mathrm{UN} / \mathrm{DFIR}, \text { Mixed }}=100 e^{-0.06 W_{\mathrm{s} 10}} R^{2}=0.194 \\
\mathrm{CR}_{\mathrm{SA} / \mathrm{DFIR}, \text { Mixed }}=100 e^{-0.04 W_{\mathrm{s} 10}} R^{2}=0.100 \\
\mathrm{CR}_{\text {PIT/DFIR,Mixed }}=100 e^{-7 E-0 W_{\mathrm{s} 10}} R^{2}=0.000\end{array}$ & $>1.0$ & 24 & $\begin{array}{l}\alpha=0.07 \\
\alpha=0.16 \\
\alpha=\text { no data }\end{array}$ \\
\hline & Snow & $\begin{array}{l}\text { CSPG }_{U N} \\
\text { CSPG }_{\text {SA }} \\
\text { CSPG }_{\text {PIT }}\end{array}$ & $\begin{array}{l}\mathrm{CR}_{\mathrm{UN} / \mathrm{DFIR}, \text { Snow }}=100 e^{-0.08 W_{\mathrm{s} 10}} R^{2}=0.412 \\
\mathrm{CR}_{\mathrm{SA} / \mathrm{DFIR}, \text { Snow }}=100 W_{\mathrm{s} 10}^{-0.02} R^{2}=0.090 \\
\mathrm{CR}_{\text {PIT/DFIR,Snow }}=100 e^{-0.01 W_{\mathrm{s} 10}} \\
R^{2}=0.024\end{array}$ & $>1.0$ & 34 & $\begin{array}{l}\alpha=6.4 \times 10^{-5} \\
\alpha=0.07 \\
\alpha=0.35\end{array}$ \\
\hline \multirow[t]{5}{*}{$\begin{array}{l}\text { Daily } \\
\text { precipitation }\end{array}$} & \multirow{3}{*}{ Rain } & $\mathrm{CSPG}_{\mathrm{UN}}$ & $\begin{array}{l}\mathrm{CR}_{\mathrm{UN} / \mathrm{DFIR}, \mathrm{Rain}}=-1.400 W_{\mathrm{s} 0.7}^{3}+2.987 W_{\mathrm{s} 0.7}^{2}-6.116 W_{\mathrm{s} 0.7}+100 \\
R^{2}=0.032\end{array}$ & \multirow{3}{*}{$>3.0$} & \multirow{3}{*}{90} & $\alpha=0.37$ \\
\hline & & CSPG $_{S A}$ & $\begin{array}{l}\mathrm{CR}_{\mathrm{SA} / \mathrm{DFIR}, \mathrm{Rain}}=-0.924 W_{\mathrm{s} 0.7}^{3}+1.158 W_{\mathrm{s} 0.7}^{2}-3.338 W_{\mathrm{s} 0.7}+100 \\
R^{2}=0.021\end{array}$ & & & $\alpha=0.55$ \\
\hline & & CSPGPIT & $\begin{array}{l}\mathrm{CR}_{\text {PIT/DFIR,Rain }}=-0.952 W_{\mathrm{s} 0.7}^{3}-1.503 W_{\mathrm{s} 0.7}^{2}+2.237 W_{\mathrm{s} 0.7}+100 \\
R^{2}=-0.00\end{array}$ & & & $\alpha=$ no data \\
\hline & Mixed & $\begin{array}{l}\text { CSPG UN }_{\text {UN }} \\
\text { CSPG }_{\text {SA }} \\
\text { CSPG }_{\text {PIT }}\end{array}$ & $\begin{array}{l}\mathrm{CR}_{\mathrm{UN} / \mathrm{DFIR}, \text { Mixed }}=100 e^{-0.12 W_{\mathrm{s} 0.7}} R^{2}=0.144 \\
\mathrm{CR}_{\mathrm{SA} / \mathrm{DFIR}, \text { Mixed }}=100 e^{-0.07 W_{\mathrm{s} 0.7}} R^{2}=0.094 \\
\mathrm{CR}_{\text {PIT/DFIR,Mixed }}=100 e^{-0.001 W_{\mathrm{s} 0.7}} R^{2}=0.003\end{array}$ & $>1.0$ & 21 & $\begin{array}{l}\alpha=0.09 \\
\alpha=0.18 \\
\alpha=\text { no data }\end{array}$ \\
\hline & Snow & $\begin{array}{l}\text { CSPG }_{U N} \\
\text { CSPG }_{S A} \\
\text { CSPGPIT }\end{array}$ & $\begin{array}{l}\mathrm{CR}_{\mathrm{UN} / \mathrm{DFIR}, \text { Snow }}=100 e^{-0.11 W_{\mathrm{s} 0.7}} R^{2}=0.477 \\
\mathrm{CR}_{\mathrm{SA} / \mathrm{DFIR}, \text { Snow }}=100 e^{-0.03 W_{\mathrm{s} 0.7}} R^{2}=0.087 \\
\mathrm{CR}_{\mathrm{PIT} / \mathrm{DFIR}, \text { Snow }}=100 e^{-0.01 W_{\mathrm{s} 0.7}} \\
R^{2}=-0.00\end{array}$ & $>1.0$ & 27 & $\begin{array}{l}\alpha=1.8 \times 10^{-4} \\
\alpha=0.14 \\
\alpha=\text { no data }\end{array}$ \\
\hline
\end{tabular}

${ }^{*} W_{\mathrm{s} 10}-$ wind speed during period of precipitation at $10 \mathrm{~m}$ height; $W_{\mathrm{s} 0.7}-$ daily mean wind speed at gauge height $(0.7 \mathrm{~m}$ for CSPG).

For the mixed precipitation events, the CR vs. $W_{\mathrm{s} 10}$ relationships are exponential (Table 4, Fig. 6). The CRs vary greatly from about 60 to $120 \%$. For the $\mathrm{CSPG}_{\mathrm{UN}}$, the exponential relationship Eq. (11) passes the $F$ test with $\alpha=0.07$, whereas for the $\mathrm{CSPG}_{\mathrm{SA}}$, the Eq. (12) $\alpha$ value is about 0.16 (Table 4).

$$
\begin{array}{ll}
\mathrm{CR}_{\mathrm{UN} / \mathrm{DFIR}, \text { Mixed }}=100 e^{-0.06 W_{\mathrm{s} 10}} & 0<W_{\mathrm{s} 10}<5.9 \\
\mathrm{CR}_{\mathrm{SA} / \mathrm{DFIR}, \text { Mixed }}=100 e^{-0.04 W_{\mathrm{s} 10}} & 0<W_{\mathrm{s} 10}<5.9
\end{array}
$$

On the daily scale, the relationships between mixed precipitation $\mathrm{CR}$ and wind speed at gauge height $\left(W_{\mathrm{s} 0.7}\right)$ are also exponential expressions (Table 4, Fig. 6). Similarly, for the CSPG $_{\mathrm{UN}}$, Eq. (13) passes the $F$ test with $\alpha<0.10$, whereas Eq. (14) with an $\alpha$ value of about 0.18 does not (Table 4).

$$
\begin{aligned}
& \mathrm{CR}_{\mathrm{UN} / \mathrm{DFIR}, \text { Mixed }}=100 e^{-0.12 W_{\mathrm{s} 0.7} 0}<W_{\mathrm{s} 0.7}<2.9 \\
& \mathrm{CR}_{\mathrm{SA} / \mathrm{DFIR}, \text { Mixed }}=100 e^{-0.07 W_{\mathrm{s} 0.7} 0}<W_{\mathrm{s} 0.7}<2.9
\end{aligned}
$$

From Eq. (3), air temperature may also affect the mixed precipitation CRs on the daily scale. Equations (15)-(16) are obtained as follows. However, these two new equations do not pass the $F$ test with $\alpha<0.20$.

$$
\begin{aligned}
\mathrm{CR}_{\mathrm{UN} / \mathrm{DFIR}, \text { Mixed }} & =13.83 W_{\mathrm{s} 0.7}^{-4.91}+1.25 T_{\max } \\
& -0.88 T_{\min }+62.21 \quad \alpha=0.20
\end{aligned}
$$

$$
\begin{aligned}
\mathrm{CR}_{\mathrm{SA} / \mathrm{DFIR}, \text { Mixed }} & =10.74 W_{\mathrm{s} 0.7}^{-4.74}+0.85 T_{\max } \\
& -0.18 T_{\min }+76.20 \quad \alpha=0.29,
\end{aligned}
$$

where $T_{\max }$ and $T_{\min }$ are the daily maximum and minimum air temperature $\left({ }^{\circ} \mathrm{C}\right)$, respectively.

For the snowfall events, the $\mathrm{CR}_{\mathrm{UN} / \mathrm{DFIR} \text {,Snow }}$ and $\mathrm{CR}_{\mathrm{SA} / \mathrm{DFIR} \text {,Snow }}$ vs. $W_{\mathrm{s} 10}$ relationships are significant (Table 4, Fig. 7). For the $\mathrm{CSPG}_{\mathrm{UN}}$, the exponential relationship Eq. (17) passes the $F$ test with $\alpha<0.001$. Equation (17) is similar to Eq. (5) suggested by Yang et al. (1991). For the $\mathrm{CSPG}_{\mathrm{SA}}$, its exponential expression in Eq. (18) passes the $F$ test at $\alpha=0.07$ (Table 4 ).

$$
\begin{array}{ll}
\mathrm{CR}_{\mathrm{UN} / \mathrm{DFIR}, \text { Snow }}=100 e^{-0.08 W_{\mathrm{s} 10}} & 0<W_{\mathrm{s} 10}<4.8 \\
\mathrm{CR}_{\mathrm{SA} / \mathrm{DFIR}, \text { Snow }}=100 e^{-0.02 W_{\mathrm{s} 10}} & 0<W_{\mathrm{s} 10}<4.8
\end{array}
$$

On the daily scale, the relationships between snowfall CRs and wind speed at gauge height $\left(W_{\mathrm{s} 0.7}\right)$ are also exponential expressions (Table 4, Fig. 7). For the $\mathrm{CSPG}_{\mathrm{UN}}$ and 

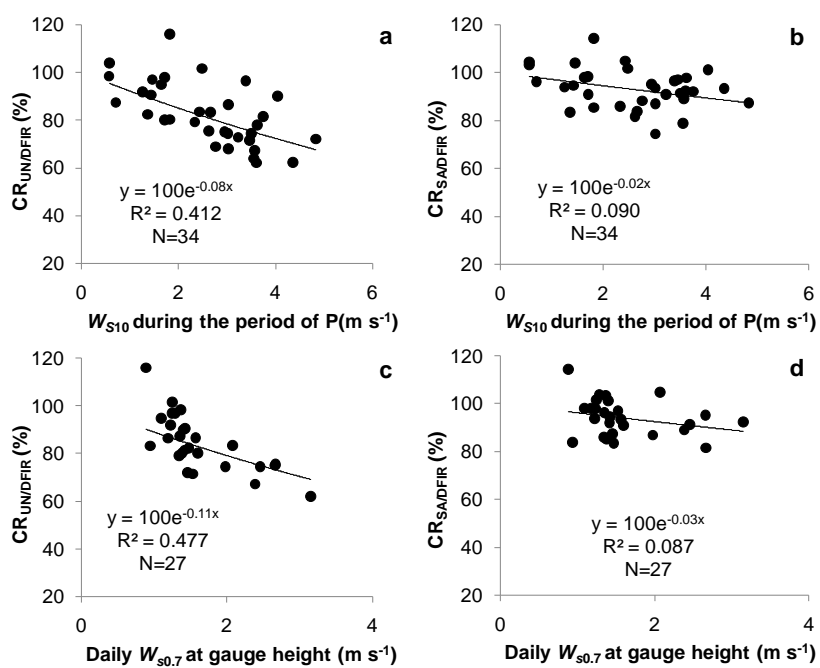

Figure 7. Catch ratios (CRs) vs. wind speed for the snowfall event $(\mathbf{a}, \mathbf{b})$ and the daily $(\mathbf{c}, \mathbf{d})$ snowfall greater than $1.0 \mathrm{~mm}$.

CSPG $_{\mathrm{SA}}$, the Eqs. (19)-(20) pass the $F$ test with $\alpha<0.001$ and $\alpha=0.14$, respectively (Table 4). Equations (17)-(19) could therefore be directly used to calibrate the wind-induced snowfall measurement errors for the $\mathrm{CSPG}_{\mathrm{UN}}$ and $\mathrm{CSPG}_{\mathrm{SA}}$.

$$
\begin{array}{ll}
\mathrm{CR}_{\mathrm{UN} / \mathrm{DFIR}, \text { Snow }}=100 e^{-0.11 W_{\mathrm{s} 0.7}} & 0<W_{\mathrm{s} 0.7}<3.1 \\
\mathrm{CR}_{\mathrm{SA} / \mathrm{DFIR}, \text { Snow }}=100 e^{-0.03 W_{\mathrm{s} 0.7}} & 0<W_{\mathrm{s} 0.7}<3.1
\end{array}
$$

Air temperature may also affect the snowfall $\mathrm{CR}$ on the daily scale as shown in Eq. (2). Equations (21)-(22) are the new equations associated with daily maximum air temperature. However, these two new equations are not better than Eqs. (19)-(20) according to their $F$ test $\alpha$ values.

$$
\begin{aligned}
\mathrm{CR}_{\mathrm{UN} / \mathrm{DFIR}, \text { Snow }}= & 42.29 W_{\mathrm{s} 0.7}^{-1.06}-1.06 T_{\max }+55.91 \\
& \alpha=4.2 \times 10^{-5}
\end{aligned}
$$

$$
\begin{gathered}
\mathrm{CR}_{\mathrm{SA} / \mathrm{DFIR}, \mathrm{Snow}}=-9.46 \ln \left(W_{\mathrm{s} 0.7}\right)-0.31 T_{\max }+98.76 \\
\alpha=0.17
\end{gathered}
$$

From the above mentioned relationships of $\mathrm{CR}_{\mathrm{UN} / \mathrm{DFIR}}$ and $\mathrm{CR}_{\mathrm{SA} / \mathrm{DFIR}}$ vs. wind speed, the following points can be drawn for our understanding. For daily rain and mixed precipitation, the relationships are not statistically significant. The use of daily mean wind speed may lead to uncertainties in gauge comparisons. Data collections and analyses on shorter timescales, such as hourly or 6-hourly, are expected to produce more reliable results, because wind speed may vary throughout the day and daily mean wind speeds may not be representative of the wind conditions over the precipitation period (Yang and Simonenko, 2014). Daily maximum and minimum temperatures should reflect the atmospheric conditions of radiation and convection to some degree, and their function in the CR vs. wind speed relationship needs further investigation in a mountain environment.

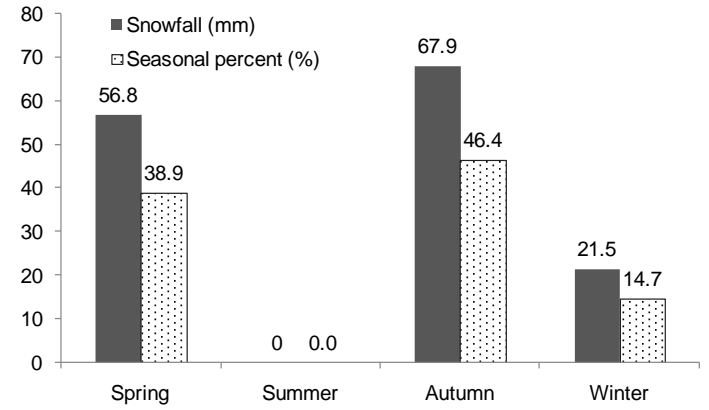

Figure 8. Seasonal snowfall and its percentage from September 2010 to April 2015 at the Hulu watershed site.

\section{Discussion}

\subsection{Comparison with other studies}

Yang et al. (1991) carried out a precipitation intercomparison experiment from 1985 to 1987 at the Tianshan site. Their results indicated that the $\mathrm{CSPG}_{\mathrm{DFIR}} / \mathrm{CSPG}_{\mathrm{UN}}$ ratios for snowfall and mixed precipitation were 1.222 and 1.160 , respectively. In the Hulu watershed, these ratios were 1.165 (Fig. 4c) and 1.072 (Fig. 3c), while those for $\mathrm{CSPG}_{\mathrm{PIT}} / \mathrm{CSPG}_{\mathrm{UN}}$ were 1.162 (Fig. 4b) and 1.082 (Fig. 3b), respectively. Similar topographic features and shading induced similar lower wind speeds and led to similar catch ratios at both sites. For the Tianshan study site, wind speed $\left(W_{\mathrm{s} 10}\right)$ on rainfall or snowfall days never exceeded $6 \mathrm{~m} \mathrm{~s}^{-1}$, and $88 \%$ of the total annual precipitation took place with wind speeds below $3 \mathrm{~m} \mathrm{~s}^{-1}$. At the Hulu watershed site, daily mean wind speeds $\left(W_{\mathrm{s} 10}\right)$ on precipitation days never exceeded $6.4 \mathrm{~m} \mathrm{~s}^{-1}$, and over $55.2 \%$ of the precipitation events occurred with daily mean wind speeds below $3 \mathrm{~m} \mathrm{~s}^{-1}$. During the periods of precipitation, the highest wind speed at $10 \mathrm{~m}$ height was about $8.8 \mathrm{~m} \mathrm{~s}^{-1}$, and over $54.2 \%$ of the precipitation events occurred with wind speeds below $3 \mathrm{~m} \mathrm{~s}^{-1}$.

As Ren et al. (2003) reported, across 30 comparison stations in China, the CSPGPIT caught $3.2 \%(1.1-7.9 \%)$ more rainfall and $11.0 \%(2.2-24.8 \%)$ more snowfall than the $\mathrm{CSPG}_{\mathrm{UN}}$. Large wind-induced differences were often observed at the mountainous western stations and in northeastern China. At the Gangcha station $\left(100^{\circ} 08^{\prime} \mathrm{E}, 37^{\circ} 20^{\prime} \mathrm{N}\right.$; $3015 \mathrm{~m}$ ), which also lies in the Qilian Mountains at a similar elevation about $200 \mathrm{~km}$ from the Hulu watershed site, the CSPGPIT caught $7.9 \%$ more rainfall and $16.8 \%$ more snowfall than the $\mathrm{CSPG}_{\mathrm{UN}}$ from 1992 to 1998. In our study, the CSPGPIT captured $4.7 \%$ more rainfall, $21.0 \%$ more snowfall and $12.1 \%$ more mixed precipitation than the $\mathrm{CSPG}_{\mathrm{UN}}$ from September 2010 to April 2015 (Table 3). The outcome presented in this study is somewhat different from that reported by Ren et al. (2003) due to differences in the wind regime. At the Gangcha station, daily mean wind speeds $\left(W_{\mathrm{s} 10}\right)$ on precipitation days during the experimental pe- 
(a)

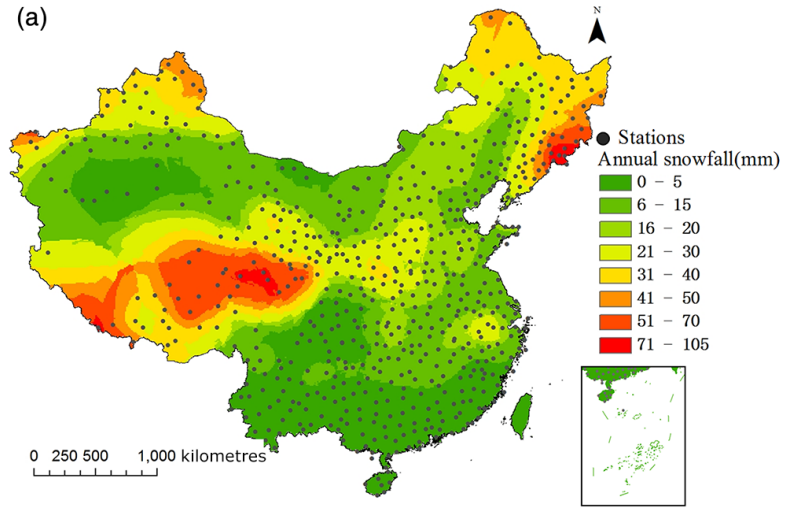

(b)

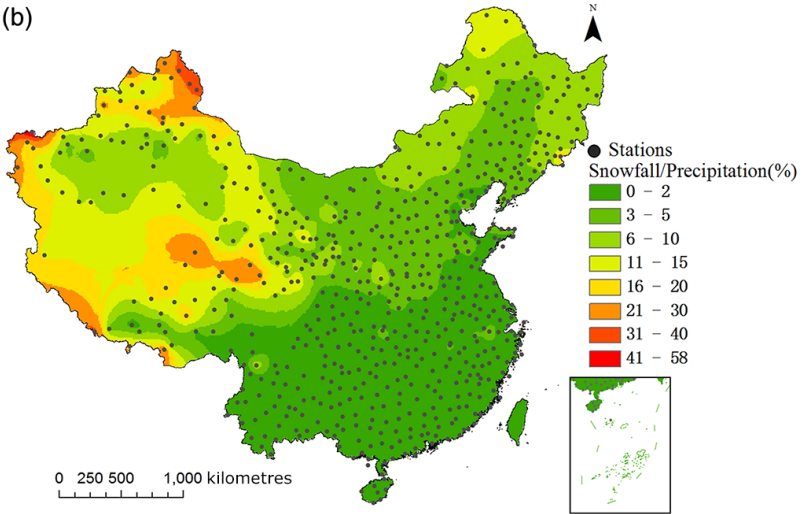

Figure 9. (a) Annual snowfall ( $\mathrm{mm})$ and (b) ratio of annual snowfall to total precipitation in China.

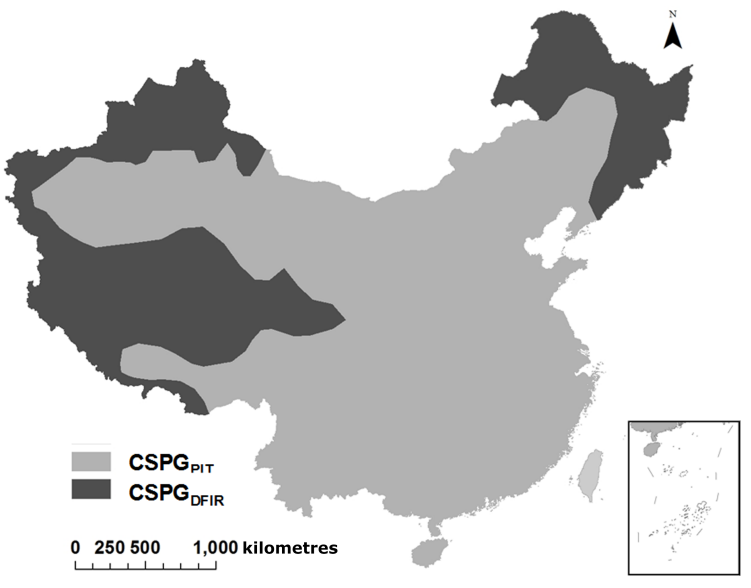

Figure 10. Applicable regions in China for the CSPGPIT and CSPGDFIR as reference gauges.

riod from 1992 to 1998 never exceeded $8.5 \mathrm{~m} \mathrm{~s}^{-1}$, and over $35.1 \%$ of the precipitation events occurred with daily mean wind speeds below $3 \mathrm{~m} \mathrm{~s}^{-1}$. The average daily mean $W_{\mathrm{s} 10}$ was about $3.4 \mathrm{~m} \mathrm{~s}^{-1}$ on precipitation days from 1992 to 1998 at the Gangcha station, whereas at the Hulu watershed site from 2010 to 2015 , the average value was about $2.9 \mathrm{~m} \mathrm{~s}^{-1}$ on precipitation days.

It is recognised that in western China, climatic and environmental conditions in the mountains vary both spatially and temporally. To understand the similarities and differences in wind-induced bias in precipitation measurements for different mountain watersheds, field experiments need to be carried out continuously. Further investigation is also necessary to consider the influence of micrometeorology on gauge observations, particularly wind distribution and turbulence across this site (Yang and Simonenko, 2014).

\subsection{CSPG $_{\text {PIT }}$ as a reference for solid precipitation}

The pit is the WMO reference configuration for liquid precipitation measurements and the DFIR is the reference configuration for solid precipitation measurements (Sevruk et al., 2009). In this study, the CSPGPIT measured more rainfall and mixed precipitation than the $\mathrm{CSPG}_{\mathrm{DFIR}}$. For snowfall, the catch ratio for CSPGPIT was 0.96, close to that of the $\mathrm{CSPG}_{\mathrm{DFIR}}$ measurement. The difference in total snowfall (43 events) between the CSPGPIT and CSPG only about $3.4 \mathrm{~mm}$ from September 2012 to April 2015 at the Hulu watershed site. The snowfall for autumn and spring was greater than for winter during the observation period at the intercomparison site (Fig. 8). The snowfall is wetter in autumn and spring than in winter, and wetter snowfall means less blowing or drifting snow. Thus the CSPGPIT could serve as a reference for liquid and solid precipitation in environments similar to that of the Hulu watershed site. Precipitation collected by the CSPGPIT would be most affected by blowing or drifting snow, inducing a faulty precipitation value (Goodison et al., 1998; Ren and Li, 2007). Previous studies have indicated, however, that for most of China, the maximum snow depth in the past 30 years has been less than $20 \mathrm{~cm}(\mathrm{Li}, 1999)$, with average snow depths below $3 \mathrm{~cm}$ (Li et al., 2008; Che et al., 2008). Figure 9 shows annual snowfall amounts and annual snowfall proportion distributions for 644 meteorological stations in China from 1960 to 1979, indicating that snowfall is concentrated in the middle and south-western Tibetan Plateau, northern Xinjiang province and north-eastern China. Statistical analysis indicates that for more than $94 \%$ of stations, solid precipitation comprises less than $15 \%$ of the annual precipitation. Ren et al. (2003) reported, that among the 2286 snowfall events, only 54 were blowing or drifting snow events, accounting for about $2.4 \%$ for 26 stations across China. Based on the regionalisation of snow drift in China, blowing or drifting snow events occur mostly on the central and south-western Tibetan Plateau, in the northern Xinjiang province and in north-eastern China (Wang and Zhang, 


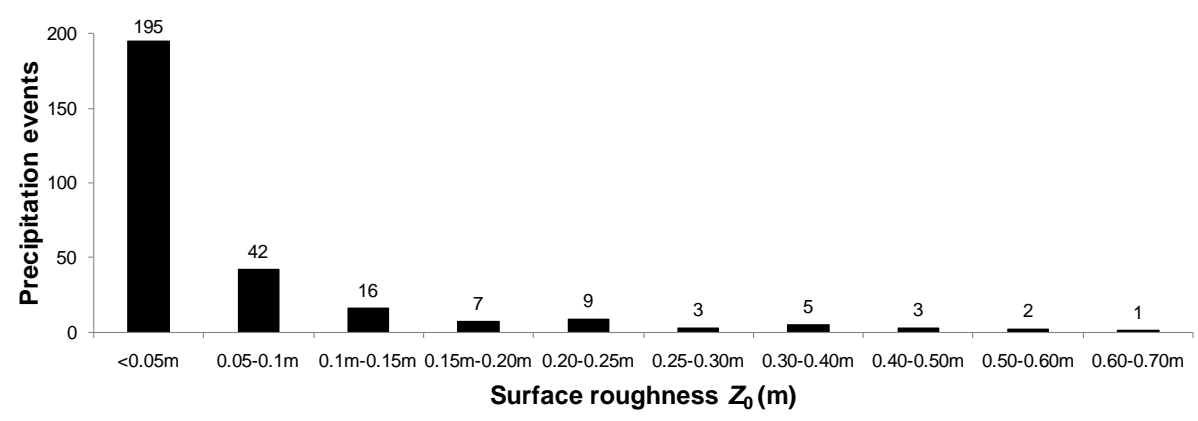

Figure 11. Surface roughness during the precipitation period from September 2012 to April 2015.

1999). In these regions, the CSPG reference gauge. In other regions, the $\mathrm{CSPG}_{\mathrm{PIT}}$ may be applicable. Based on the CMA snowfall and snow depth data, and the regionalisation of snow drift in China, the applicable regions for the $\mathrm{CSPG}_{\mathrm{PIT}}$ and $\mathrm{CSPG}_{\mathrm{DFIR}}$ as reference gauges are shown in Fig. 10.

\subsection{Limitations of this experiment}

Although the measurement procedures were based on the CMA's standard, manual observations were infrequent, and as a result, some precipitation events were summarised as single events, especially in the evenings. The automatic meteorological tower could observe precipitation and wind speeds half-hourly during the precipitation period, but the $\mathrm{CSPG}_{\mathrm{UN}}, \mathrm{CSPG}_{\mathrm{SA}}, \mathrm{CSPG}_{\mathrm{PIT}}$ and $\mathrm{CSPG}_{\mathrm{DFIR}}$ were observed only twice per day. In this field experiment, the precipitation phases were also distinguished by observers. This method is somewhat imprecise although this has remained the traditional method since the 1950s at the CMA stations (CMA, 2007b). Automatic sensors will also be important to detect precipitation types at operational and research networks (Yang and Simonenko, 2014).

The wind speeds at gauge height and at $10 \mathrm{~m}$ height were not observed directly but rather calculated from the observed data at 1.5 and $2.5 \mathrm{~m}$ heights according to the MoninObukhov theory and the gradient method (Eq. 8). Although this method is widely used, it is effective only under neutral atmospheric conditions. For the precipitation period from September 2012 to April 2015, the $Z_{0}$ was calculated using Eq. (9). The results showed the $Z_{0}$ to be about $0.06 \mathrm{~m}$ on average but it varied from nearly zero to $0.67 \mathrm{~m}$. As shown in Fig. 11, in about 68.9 and $95.1 \%$ of instances, the $Z_{0}$ was lower than 0.05 and $0.25 \mathrm{~m}$, respectively. In rare cases when the $Z_{0}$ was very large, as shown in Fig. 11 , the $Z_{0}$ was arbitrarily assigned $1 / 2$ of the grass height $(h)$ at the site based on the equation $Z_{0}=0.5 h L_{e}$ provided by Lettau (1969). The very large $Z_{0}$ values usually appeared in late August and early September when the vegetation coverage $\left(L_{e}\right)$ was close to $100 \%$ at the Hulu watershed site.

\section{Conclusions}

This study focused on wind-induced bias in precipitation measurements by CSPGs specifically in a high mountain environment. The precipitation intercomparison experiment in the Hulu watershed of the Qilian Mountains indicated that the CSPGPIT caught more rainfall, mixed precipitation and total precipitation but less snowfall than the CSPG $_{\text {DFIR }}$. From most to least rainfall and mixed precipitation measured, their ranking was $\mathrm{CSPG}_{\mathrm{PIT}}>\mathrm{CSPG}_{\mathrm{DFIR}}>\mathrm{CSPG}_{\mathrm{SA}}>\mathrm{CSPG}_{\mathrm{UN}}$, whereas in the snowy season, better wind shielding increased the snow catch, leading to $\mathrm{CSPG}_{\text {DFIR }}>\mathrm{CSPG}_{\text {PIT }}>\mathrm{CSPG}_{\mathrm{SA}}>\mathrm{CSPG}_{\mathrm{UN}}$. The measured daily precipitation by shielded gauges increases linearly with that of unshielded gauges. For solid precipitation, some non-linear factors interfere with the linear relationship to reduce the linear correlation coefficient.

In regions with lower snowfall, such as the southern and central parts of China (Zhang and Zhong, 2014), and in regions with a similar climate and environment to that of the Hulu watershed site, the CSPGPIT could be used as a reference gauge because of its high catch ratio, simplicity and lower maintenance requirements. In north-eastern China, northern Xinjiang province and the central and south-western Tibetan Plateau where snowfall often occurs, the best choice of reference gauge would be the CSPGPIT for rainfall and the CSPG DFIR for snowfall observations.

The catch ratio vs. wind speed relationship for different precipitation types is quantified by cubic polynomials and exponential functions. The CR $\mathrm{CIT}_{\text {TDFIR }}$ does not have a significant relationship to wind speed, indicating that both PIT and DFIR are effective in preventing wind from influencing the precipitation gauge catch. For daily rain and mixed precipitation, the relationships are not statistically significant. Daily maximum and minimum temperatures should reflect the atmospheric conditions of radiation and convection to some degree, and their function in the CR vs. wind speed relationship needs further investigation in mountain environments. It is recognised that in western China, the climatic and environmental conditions in the mountains vary both spatially and temporally. To understand the similarities and differences 
among wind-induced biases in precipitation measurements for the different mountain watersheds in western China, field experiments and modelling of wind fields need to be carried out continuously.

\section{The Supplement related to this article is available online at doi:10.5194/tc-9-1995-2015-supplement.}

Acknowledgements. This study was supported primarily by the National Basic Research Program of China (2013CBA01806) and the National Natural Sciences Foundation of China (91025011, 41222001, 91225302 and 41401078).

Edited by: D. Yang

\section{References}

Aaltonen, A., Elomaa, E., Tuominen, A., and Valkovuori, P.: Measurement of precipitation, in: Proceedings of the Symposium on Precipitation and Evaporation, edited by: Sevruk, B. and Lapin, M., Slovak Hydrometeorlogical Institute and Swiss Federal Institute of Technology, Bratislava, Slovakia, 42-46, 1993.

Bagnold, R. A.: The Physics of Blown Sand and Desertdunes, Methuen, New York, 85-95, 1941.

Charnes, A., Frome, E. L., and Yu, P. L.: The equivalence of generalized least squares and maximum likelihood estimates in the exponential family, J. Am. Stat. Assoc., 71, 169-171, 1976.

Che, T., Li, X., Jin, R., Armstrong, R., and Zhang, T.: Snow depth derived from passive microwave remote-sensing data in China, Ann. Glaciol., 49, 145-154, 2008.

Chen, R., Song, Y., Kang, E., Han, C., Liu, J., Yang, Y., Qing, W., and Liu, Z.: A Cryosphere-Hydrology observation system in a small alpine watershed in the Qilian Mountains of China and its meteorological gradient, Arct. Antarct. Alp. Res., 46, 505-523, doi:10.1657/1938-4246-46.2.505, 2014.

CMA - China Meteorological Administration: Specifications for surface meteorological observation Part 8: Measurement of precipitation (QX/T 52-2007), China Meteorological Press, Beijing, 2007a.

CMA - China Meteorological Administration: Specifications for surface meteorological observation Part 4: Observation of weather phenomenon (QX/T 48-2007), China Meteorological Press, Beijing, 2007b.

Ding, Y., Yang, D., Ye, B., and Wang, N.: Effects of bias correction on precipitation trend over China, J. Geophys. Res., 112, D13116, doi:10.1029/2006JD007938, 2007.

Dyer, A. J. and Bradley, E. F.: An alternative analysis of fluxgradient relationships at the 1976 ITCE, Bound.-Lay. Meteorol., 22, 3-19, doi:10.1007/BF00128053, 1982.

Golubev, V. S.: On the problem of actual precipitation measurements at the observations site, in: Proceeding of the International Workshop on the Correction of Precipitation Measurements WMO/TD 104, World Meteorological Organization, Geneva, Switzerland, 61-64, 1985.
Goodison, B. E., Louie, B. P. Y. T., and Yang, D.: WMO solid precipitation measurement intercomparison: Final report, Instrum. and Obs. Methods Rep. 67/Tech. Doc. 872, World Meteorol. Organ., Geneva, Switzerland, 1998.

IBM Corp: IBM SPSS Statistics for Windows, Version 19.0, IBM Corp, Armonk, NY, USA, 2010.

Lanza, L. G., Leroy, M., Alexandropoulos, C., Stagi, L., and Wauben, U.: WMO Laboratory Intercomparison of Rainfall Intensity Gauges - Final Report, IOM Report No. 84, WMO/TD No. 1304, WMO, Geneva, Switzerland, 2005.

Lettau, H.: Note on aerodynamic roughness-parameter estimation on the basis of roughness element description, J. Appl. Areorol., 8, 828-832, 1969.

Li, P.:. Variation of snow water resources in northwestern China, 1951-1997, Sci. China Ser. D, 42, 73-79, 1999.

Li, X., Cheng, G., Jin, H., Kang, E., Che, T., Jin, R., Wu, L., Nan, Z., Wang, J., and Shen, Y.: Cryospheric change in China, Global Planet. Change, 62, 210-218, doi:10.1016/j.gloplacha.2008.02.001, 2008.

Ma, Y., Zhang, Y., Yang, D., and Farhan, S.: Precipitation bias variability versus various gauges under different climatic conditions over the Third Pole Environment (TPE) region, Int. J. Climatol., 35, 1201-1211, doi:10.1002/joc.4045, 2014.

Metcalfe, J. R. and Goodison, B. E.: Correction of Canadian winter precipitation data. Preprints, in: Eighth Symp. on Meteorological Observations and Instrumentation, Am. Meteorol. Soc., Anaheim, CA, 338-343, 1993.

Ren, Z. and Li, M.: Errors and correction of precipitation measurements in China, Adv. Atmos. Sci., 24, 449-458, doi:10.1007/s00376-007-0449-3, 2007.

Ren, Z., Wang, G., Zou, F., and Zhang, H.: The research of precipitation measurement errors in China, Acta Meteorol. Sin., 61, 621-627, 2003.

Rodda, J. C.: The rainfall measurement problem, in: Proceedings of IAHS, Publication No. 78, General Assembly, Bern, 215-231, 1967.

Rodda, J. C.: Annotated Bibliography on Precipitation Measurement Instruments, WMO-No. 343, World Meteorol. Org, Geneva, Switzerland, 1973.

Sevruk, B. and Hamon, W. R.: International comparison of national precipitation gauges with a reference pit gauge, instruments and observing methods Rep. 17, World Meteorol. Org., Geneva, 1984.

Sevruk, B., Ondrás, M., and Chvíla, B.: The WMO precipitation measurement intercomparisons, Atmos. Res., 92, 376-380, doi:10.1016/j.atmosres.2009.01.016, 2009.

Snedecor, G. and Cochran, W.: Statistical methods, Iowa State University Press, Iowa, 1989.

Struzer, L. R.: Practicability analysis of rain gauge international comparison test results, Trans. Voyeykov Main Geophys. Observ., 260, 77-94, 1971.

Sugiura, K., Yang, D., and Ohata, T.: Systematic error aspects of gauge-measured solid precipitation in the Arctic, Barrow, Alaska, Geophys. Res. Lett., 30, 1192, doi:10.1029/2002GL015547, 2003.

Tian, X., Dai, A., Yang, D., and Xie, Z.: Effects of precipitationbias corrections on surface hydrology over northern latitudes, J. Geophys. Res., 112, D14101, doi:10.1029/2007JD008420, 2007. 
Wang, Z. and Zhang, Z.: Regionalization of snow drift in China, J. Mt. Sci., 17, 312-317, 1999.

Wolff, A. M., Nitu, R., Earle, M., Joe, P., Kochendorfer, J., Rasmussen, R., Reverdin, A., Sminth, C., Yang, D., and the SPICETEAM: WMO Solid Precipitation Intercomparison Experiment (SPICE): Report on the SPICE Field Working Reference System for precipitation amount, WMO, IOM No. 116, TECO2014, World Meteorological Organization, Geneva, Switzerland, 2014.

Yang, D.: Research on analysis and correction of systematic errors in precipitation measurement in Urumqi River basin, Tianshan, $\mathrm{PhD}$ thesis, Lanzhou Institute of Glaciology and Geocryology, Chinese Academy of Sciences, Lanzhou, China, 169 pp., 1988.

Yang, D.: Double-Fence Intercomparison Reference (DFIR) vs. Bush Gauge for "true" snowfall measurement, J. Hydrol., 509, 94-100, doi:10.1016/j.jhydrol.2013.08.052, 2014.

Yang, D. and Simonenko, A.: Comparison of winter precipitation measurements by six Tretyakov gauges at the Valdai experimental site, Atmos.-Ocean, 52, 39-53, doi:10.1080/07055900.2013.865156, 2014.

Yang, D., Shi, Y., Kang, E., Zhang, Y., and Yang, X.: Results of solid precipitation measurement intercomparison in the Alpine area of Urumqi River basin, Chinese Sci. Bull., 36, 1105-1109, 1991.

Yang, D., Metcalfe, J. R., Goodison, B. E., and Mekis, E.: An evaluation of Double-Fence Intercomparison Reference (DFIR) gauge, in: Proceedings of Eastern Snow Conference, 50th Meeting, Quebec City, 105-111, 1993.
Yang, D., Goodison, B. E., Metcalfe, J. R., Golubev, V. S., Elomaa, E., Gunther, T. H., Bates, R., Pangburn, T., Hanson, C. L., Emerson, D., Copaciu, V., and Milkovic, J.: Accuracy of Tretyakov precipitation gauge: Results of WMO intercomparison, Hydrol. Process., 9, 877-895, doi:10.1002/hyp.3360090805, 1995.

Yang, D., Goodison, B. E., Metcalfe, J. R., Louie, P., Leavesley, G., Emerson, D., Hanson, C. L., Golubev, S. S., Elomaa, E., Gunthter, T., Pangburn, T., Kang, E., and Milkovic, J.: Quantification of precipitation measurement discontinuity induced by wind shields on national gauges, Water Resour. Res., 35, 491508, doi:10.1029/1998WR900042, 1999.

Ye, B., Yang, D., Ding, Y., Han, T., and Koike, T.: A bias-corrected precipitation climatology for China, J. Hydrometeorol., 5, 11471160, doi:10.1175/JHM-366.1, 2004.

Ye, B., Yang, D., and Ma, L.: Effect of precipitation bias correction on water budget calculation in Upper YellowRiver, China, Environ. Res. Lett., 7, 025201, doi:10.1088/1748-9326/7/2/025201, 2012.

Zhang, T. and Zhong, X.: Classification and regionalization of the seasonal snow cover across the Eurasian Continent, J. Glaciol. Geocryol., 36, 481-490, 2014.

Zhang, Y., Ohata, T., Yang, D., and Davaa, G.: Bias correction of daily precipitation measurements for Mongolia, Hydrol. Process., 18, 2991-3005, doi:10.1002/hyp.5745, 2004. 